\title{
A impossibilidade de se dizer o indizível: reflexões sobre o duplo na novela "O unicórnio", de Hilda Hilst
}

Willian André ${ }^{1}$

O mundo nos escapa porque volta a ser ele mesmo.

Albert Camus

Publicada em Fluxo-floema (1970), primeiro volume em prosa da autora, a novela "O unicórnio", de Hilda Hilst, embrenha-se por um fluxo de consciência intrincado. As divagações e memórias que nos são apresentadas ao longo de seu único parágrafo - que se estende por páginas a fio - não permitem a delimitação de um enredo: a partir de sua estrutura inicial, percebemos apenas a voz de uma narradora - cujo nome desconhecemos - intercalada por uma segunda voz (que parece pertencer também a uma mulher), como se estivessem constituindo uma espécie de entrevista/diálogo. Com um tom amargo, e muitas vezes poético, a narradora conta à outra fragmentos de sua vida, relacionando-os com frequência a três personagens que fizeram parte de seu passado, aos quais ela chama "meu companheiro", "minha irmã lésbica" e "meu irmão pederasta" (principalmente em relação aos dois últimos, ela parece guardar forte ressentimento). Em certo ponto da narrativa, seu corpo começa a mudar, e ela de repente se vê transformada em um enorme unicórnio. Guardando poucas semelhanças com as figurações do unicórnio que permeiam nosso imaginário, a besta que brota da metamorfose é suja e desproporcional, e sob a insólita égide dessa nova forma prosseguem as divagações da narradora até o fim da novela, que a surpreende em sua morte.

A princípio, é a metamorfose que nos interessa. Essa súbita transformação da narradora em unicórnio, a entendemos aqui como manifestação do duplo no texto estudado. Antes de dar início à leitura da novela, portanto, consideramos pertinente tecer algumas considerações acerca da presença do duplo na literatura, e o fazemos com base nas palavras de Nicole Fernandez Bravo, que discorre sobre o tema no

${ }^{1}$ Doutorando do Programa de Pós-graduação em Letras - Estudos Literários da Universidade Estadual de Londrina (UEL), Londrina, PR, Brasil. Bolsista Capes. E-mail: willianandreh@hotmail.com 
Dicionário de mitos literários organizado por Pierre Brunel. Segundo a autora, é frequente o entrelaçamento do duplo com situações que envolvem metamorfose:

O tema da metamorfose e sua relação com o animal cruza-se aqui com o mito do duplo. O homem traz em si seu animal (como vemos em Lokis [1869], de Mérimée). Ele aparece facilmente no século XX como um mutante (por exemplo, em Die Verwandlung [A Metamorfose, 1911] de Kafka, em Axolotl [1963] de J. Cortazar) que se torna prisioneiro de um outro corpo, ou mesmo se transforma numa parte de corpo (em Nos [O nariz, 1836], de Gogol, em The breast [O seio, 1972], de P. Roth), sem degradação do que constitui a característica própria do homem: o pensamento (Bravo, 2005, p. 281).

Essa "relação com o animal" a que se refere o excerto remeteria, a princípio, a uma "união primitiva", à "lembrança de uma simbiose entre o animal e o humano" (Bravo, 2005, p. 262), que carrega uma ideia de totalidade: o amálgama do eu com o outro, o casamento entre homem e natureza. Pensando dessa forma, o desabrochar do duplo pelas vias da metamorfose implicaria a "busca do melhor eu" (Bravo, 2005, p. 275). Como veremos nas próximas páginas, a metamorfose que ocorre em "O unicórnio" pode, de fato, significar uma tentativa da narradora de buscar uma "versão" melhor de si. Essa busca, todavia, está fadada ao fracasso: uma das grandes problemáticas instauradas pela novela é a fragmentação da identidade - a impossibilidade demonstrada pela narradora de enxergar-se como ser homogêneo. $\mathrm{O}$ "melhor eu", dessa forma, seria aqui um eu em que essa homogeneidade fosse perceptível. Por mais que se embrenhe em sua busca, todavia, a impressão de totalidade pretendida pela narradora não é alcançada.

Contemplando as diversas facetas assumidas pelo duplo em literaturas de diferentes épocas, Bravo assinala: "A partir do término do século XVI, o duplo começa a representar o heterogêneo, com a divisão do eu chegando à quebra da unidade (século XIX) e permitindo até mesmo um fracionamento infinito (século XX)" (Bravo, 2005, p. 264). É justamente desse duplo enquanto evidência de um fracionamento infinito que tratamos aqui. Conforme Bravo, "[a] abertura para o espaço interior do ser [...] força ao abandono progressivo do postulado da unidade da consciência, da identidade de um sujeito, única e transparente" (Bravo, 2005, p. 267). Frente à súbita impossibilidade de construir uma representação totalizante do mundo que o cerca, o sujeito 
moderno vê-se impedido de enxergar também em si próprio uma identidade homogênea. Refletindo o caráter fragmentário de tudo o que o cerca, acaba por fracionar-se, multiplicar-se em infindáveis outros eus. Dessa forma, “[o] eu soberano que se expressava no cogito dá lugar ao 'quem fala por mim?" (Bravo, 2005, p. 279).

A autora observa, ainda, que há duas formas mais imediatas de encarar esse fracionamento. A primeira delas carrega certo otimismo: aceitar o esfacelamento da unidade como uma perspectiva diferenciada de se experienciar o mundo. O exemplo utilizado é o romance $O$ lobo da estepe, de Hermann Hesse (Der Steppenwolf, 1927): “[É] preciso superar o mito da unidade do eu, diz Hesse, a projeção alienante da unidade do corpo naquela do espírito; somos feitos de uma multiplicidade de almas" (Bravo, 2005, p. 281). A outra interpretação possível, segundo Bravo, é mais sombria: a "eliminação do eu pela apropriação do duplo" (Bravo, 2005, p. 281). Como exemplo desse "apagar-se do eu", ela menciona Samuel Beckett, autor irlandês cuja obra possui um teor bastante próximo àquele encontrado nos textos de Hilda Hilst. Comentando as narrativas de Beckett, Bravo observa:

Aquele que diz "eu" trai-se forçosamente, sem controle sobre todas as vozes que o habitam e falam a torto e a direito dentro dele. O eu é esvaziado de sua substância, esvaziado de ser, e já não aparecem em cena mais do que tecidos esparsos que se fazem passar pelo eu. Estamos aqui nos antípodas da ambição totalizadora dos românticos, do mito do eu infinito em consonância com o mundo. $\mathrm{O}$ duplo simboliza a dúvida sobre o real. $\mathrm{O}$ eu, puro discurso, está no cruzamento de uma trama de vozes (Bravo, 2005, p. 283).

Tais reflexões parecem conceder-nos medida adequada para pensar a manifestação do duplo em "O unicórnio", pois, assim como ocorre nos escritos de Beckett, também na narrativa hilstiana se dissolve o eu homogêneo, detentor das verdades e certezas, dando lugar a um conjunto de vozes confusas, órfãs, que provocam a constante sensação de instabilidade. A fragmentação é marca presente ao longo de toda a narrativa: a começar pela própria voz que narra, que não é apenas uma. Como já observamos, divide tal função com a narradora uma segunda voz, pertencente a uma interlocutora/entrevistadora, como podemos perceber logo nas primeiras linhas da novela:

Eu estou dentro do que vê. Eu estou dentro de alguma coisa que faz a ação de ver. Vejo que essa coisa vê algo que lhe traz 
sofrimento. Caminho sobre a coisa. A coisa encolhe-se. Ele era um jesuíta? Quem? Esse que maltratou a Teresa D’Ávila? Sim, ele era um jesuíta. Vontade de falar a cada hora daqueles dois irmãos. Isso te dá prazer? Não, nenhum prazer (Hilst, 2003a, p. 147).

O texto é iniciado por uma sequência de frases curtas, por meio das quais a narradora tenta expressar/pôr em palavras uma experiência que não lhe é muito clara: ela diz que está "dentro de alguma coisa que faz a ação de ver". Diz que caminha sobre a coisa e que a coisa se encolhe, mas não é capaz de explicar o que é a coisa. Súbito, uma segunda voz irrompe: "Ele era um jesuíta?". Essa voz causa um efeito de interrupção nas divagações a respeito da "coisa" em que se embrenhava a narradora, e sugere que o diálogo/entrevista que a partir de então começamos a acompanhar já vinha se desenvolvendo antes, em um momento anterior à narrativa. Afinal, a pergunta "Ele era um jesuíta?" parece remeter/dar continuidade a um assunto já iniciado. A resposta da narradora ao questionamento permite-nos vislumbrar com maior clareza esse assunto de que tratavam: "Quem? Esse que maltratou a Teresa d'Ávila? Sim, ele era um jesuíta". A referência ao nome de Teresa d'Ávila sugere, portanto, que a conversa girava em torno da vida da famosa religiosa espanhola que viveu no século XVI.

Logo após responder a pergunta feita pela interlocutora, a narradora propõe, de forma abrupta, nova mudança no direcionamento do diálogo: "Vontade de falar a cada hora daqueles dois irmãos", sentença que é seguida por mais uma pergunta: "Isso te dá prazer?", que leva à resposta: "Não, nenhum prazer". "Aqueles dois irmãos" sobre os quais a narradora sente vontade de falar são os já mencionados "irmão pederasta" e "irmã lésbica". Muitas das lembranças que ela trará à tona circundarão, como já observamos, tais personagens. Não nos atenhamos, todavia, à continuidade do diálogo. $\mathrm{O}$ que pretendemos demonstrar, ao propor o esmiuçar das primeiras linhas da novela, é o quanto a fragmentação se faz presente em sua constituição. Podemos identificar pelo menos dois níveis de fragmentação no excerto analisado: primeiro, como já observamos, no fato de a narrativa fracionar-se, desdobrar-se em duas vozes. Segundo, na constante mudança de temas que permeia a conversa mantida pelas duas personagens.

Esse caráter fragmentário do texto parece possuir reflexos na identidade da própria narradora. Em certo trecho, lembrando-se novamente dos dois irmãos, ela se dirige à interlocutora: "Você sabe 
que eles ficaram com todos os meus livros? Não devolveram nenhum? Um só: 'o herói de mil caras'. Eles também sabem quem eu sou, mil caras sim senhores, mil caras para suportar, gozar e salvar mil situações" (Hilst, 2003a, p. 168). O título do livro mencionado é uma provável referência à obra $O$ herói de mil faces (The hero of a thousand faces,1949)., de Joseph Campbell, que consiste num estudo dos temas que se repetem nas diferentes mitologias, partindo de um ponto de vista psicológico. Para além da contextualização, todavia, a referência parece evidenciar tanto a fragmentação da identidade da narradora quanto a consciência que ela possui dessa fragmentação. Afinal, assumir-se como possuidora de "mil caras" é assumir a impossibilidade de enxergar-se como ser homogêneo. "Mil caras para suportar, gozar e salvar mil situações", diz ela, talvez denunciando a percepção da existência como um grande baile de máscaras.

Provável fruto dessa impossibilidade de enxergar em si uma totalidade coesa, rege as linhas de "O unicórnio" certa incapacidade de significar, de expressar-se com clareza: "Ah, como eu desejaria ser uma só, como seria bom ser inteiriça, fazer-me entender, ter uma linguagem simples como um ovo. Um ovo? É, um ovo é simples, a casca por fora, a gema e a clara por dentro" (Hilst, 2003a, p. 148). O excerto recupera a menção à identidade multifacetada: a narradora não é capaz de ser "uma só". Portadora de mil caras, não é capaz de fazer-se entender. Parece relacionar-se à ideia da fragmentação, dessa forma, a ideia de uma linguagem limitada: não ver o mundo como coisa homogênea leva à incapacidade de ver em si própria um eu "inteiriço", e culmina na impossibilidade de expressar-se também de forma inteiriça. A narradora não pode tomar mão de "uma linguagem simples como um ovo" porque é dona de uma identidade complexa. O abandono de uma máscara fixa e a aceitação das "mil caras", assim, leva à impossibilidade de se expressar.

A partir dessas reflexões, chegamos à experiência da linguagem como falha. O conflito existencial configurado na experiência dessa narradora sem nome e sem identidade definida traduz-se, na elaboração da linguagem hilstiana, em termos de impossibilidade. A forma estilhaçada em que se apresenta a narrativa de "O unicórnio", multiplicando-se em fragmentos e vozes, denuncia a incapacidade dessa linguagem de constituir um todo plenamente compreensível. Deixamos, subitamente, de concebê-la como grande desveladora das verdades 
ocultas do mundo, e percebemos sua condição mais profunda, que é de ser limitada: diante de um mundo inapreensível, criamos a linguagem para "tentar compreender" (ou para "tentar significar"). Em nenhum momento, todavia, conseguimos desvendar a verdade sobre as coisas: o que fazemos é criar nossa própria verdade, construir uma única interpretação de um grande mosaico que se abre a interpretações infinitas. Enveredando-se por essas trilhas tortuosas, Nietzsche reflete, em "Acerca da verdade e da mentira no sentido extramoral":

Que é então a verdade? Um exército móvel de metáforas, de metonímias, de antropomorfismos, numa palavra, uma soma de relações humanas que foram poética e retoricamente intensificadas, transportadas e adornadas e que depois de um longo uso parecem a um povo fixas, canónicas e vinculativas: as verdades são ilusões que foram esquecidas enquanto tais, metáforas que foram gastas e que ficaram esvaziadas do seu sentido, moedas que perderam o seu cunho e que agora são consideradas, não já como moedas, mas como metal (Nietzsche, 1997, p. 221).

Ao longo de seu ensaio, de 1873, o autor alemão reflete sobre a condição parcial de nossas verdades: "Julgamos saber algo das próprias coisas quando falamos de árvores, cores, neve e flores e, no entanto, não dispomos senão de metáforas das coisas que não correspondem de forma alguma às essencialidades primordiais" (Nietzsche, 1997, p. 219220). A linguagem passa a ser entendida, assim, como a ferramenta de que nos valemos para atribuir algum significado às coisas ao nosso redor, mas ao mesmo tempo desvela-se a pungente consciência de que há um abismo intransponível entre o mundo que pretendemos nomear/significar e essa ferramenta de que tomamos mão para fazê-lo. Poderíamos dizer que a narrativa de "O unicórnio" permite-nos um vislumbre vertiginoso desse mesmo abismo.

O grande problema de pensar nossas verdades como "ilusões que foram esquecidas enquanto tais", recuperando as palavras de Nietzsche, é o despertar da consciência de que nossa linguagem não é capaz de ir até onde pressupúnhamos. É perceber que não conhecemos o mundo de fato, mas sim uma versão que criamos dele. Que há algo para além dessa nossa interpretação, e que esse algo além permanecerá para sempre inalcançável, inexprimível - pois a linguagem é limitada, não dá conta de nomear aquilo que é inominável. O mundo, observa Rosset em Le monde et ses remèdes, fecha-se ríspido em seu silêncio. Um silêncio 
gratuito (Rosset, 2000, p. 47), que não permite interpretações derradeiras, tornando impossível a comunicação e traduzindo-se em fonte de angústia. Um silêncio, como dirá Hilst em outro texto, "feito do escuro das vísceras" (Hilst, 2003b, p. 117).

O silêncio nos agride por conta do vazio que representa, e nós devolvemos a agressão tentando preencher o vazio. Em face da gratuidade, tentamos criar uma explicação. Em face da quietude, tentamos fazer barulho. Em face do escuro, tentamos fazer luz. Há momentos, todavia, em que as sombras persistem sobre nossas pálidas tentativas, desferindo-nos um bofetão, evidenciando o absurdo das coisas, como observa Camus. O autor de $O$ mito de Sísifo reflete: "O fosso entre a certeza que tenho da minha existência e o conteúdo que tento dar a essa segurança jamais será superado" (Camus, 2008, p. 33). A percepção de que existe de fato esse fosso, todavia, só surge a partir do momento em que o emprego da linguagem é entendido como a tentativa de se explicar aquilo que não pode ser explicado:

Pensar é antes de mais nada querer criar um mundo (ou limitar o próprio, o que dá no mesmo). É partir do desacordo fundamental que separa o homem de sua experiência, para encontrar um terreno de entendimento segundo a sua nostalgia, um universo engessado de razões ou iluminado por analogias que permita resolver o divórcio insuportável (Camus, 2008, p. 114-115).

Como demonstram as páginas da novela aqui estudada, o divórcio insuportável não pode ser resolvido. Camus pondera que o absurdo brota do "confronto entre o irracional e o desejo desvairado de clareza cujo apelo ressoa no mais profundo do homem" (Camus, 2008, p. 35). Em outras palavras, a existência se torna absurda quando percebemos que nossa linguagem não passa de um exército móvel de metáforas gastas, que não nos permite penetrar o silêncio irracional do mundo. Para além dos limites de nossa linguagem está o nada, o indizível. E tudo o que podemos dizer, no final, é que há o indizível. Dizer o indizível, todavia, não podemos.

Nas linhas fragmentadas de "O unicórnio", é justamente esse o grito que ecoa: "há o indizível". A cada estrutura confusa, a cada frase mutilada, a cada pensamento que não se completa. Mergulhando cada vez mais fundo nos abismos de uma interioridade intraduzível (por ser, na verdade, incaptável), a linguagem lapidada por Hilst acaba imbuindose de certo aspecto de "prosa poética", unido à fragmentação cargas de um lirismo que tenta em vão pôr o abismo interior em palavras. O fluxo 
de consciência descontrolado que constitui a novela evidencia, assim, a experiência da linguagem levada à exaustão. Pois é o levá-la à exaustão que a torna fragmentada: na tentativa desesperada de fazer do mundo um todo coeso, a narradora força a linguagem até seus limites, e por ser impossível chegar à homogeneidade esperada, plena de significado, e por haver a consciência de que ainda resta alguma coisa para além daquilo que se tentou expressar, brota de seu âmago uma narrativa estilhaçada - a voz de uma identidade possuidora de "mil caras". Em certo momento, a narradora relembra um passeio com o irmão pederasta:

Os vegetais sentem dor, você sabia? Eu disse isso para o irmão pederasta. Sabe o que ele fez? Ele enterrou o canivete na figueira e enquanto escorria uma gosma clara, ele dizia: existir é sentir dor, existir não é ficar ao sol, imóvel, é morrer e renascer a cada dia, é verter sangue, minha amada irmã. Não, não faça isso, é horrível. Ah, tolinha, ela não sente a dor como nós sentimos, seja racional, a dor é patrimônio nosso, é assim: eu sinto dor e por isso eu existo com esse meu contorno. Eu sinto dor e todos os dias recebo vários golpes que me provocarão infinitas dores. Recebo golpes. Golpeio-me. Atiro golpes. Existir com esse meu contorno é ferirse, é agredir as múltiplas formas dentro de mim mesmo, é não dar sossego às várias caras que irrompem em mim de manhã à noite (Hilst, 2003a, p. 171-172).

As palavras do personagem parecem evidenciar a consciência de seu confronto diário com o silêncio do mundo: "eu sinto dor e por isso existo com esse meu contorno". Esse "contorno" a que se refere o irmão pederasta é o contorno de uma identidade multifacetada: também ele, como a narradora, é um "herói de mil caras" - que todos os dias recebe vários golpes que provocarão infinitas dores. A dor irrompe da consciência de ser impossível completar qualquer coisa. É um patrimônio humano. Marca de existências fragmentadas que morrem e renascem a cada dia, que recebem e atiram golpes, que mantêm a ferida aberta. Agredir as múltiplas formas dentro de nós mesmos é dar vazão à existência de infinitos eus que irrompem a cada instante. É "não dar sossego" a esses infinitos eus: perceber a impossibilidade de se dizer o indizível é viver em desassossego.

São estas reflexões que nos levam ao aflorar do duplo na narrativa. Como se para potencializar a fragmentação de sua identidade, a narradora começa a sentir seu corpo mudar: "Estou no meu canto mas 
sinto que o meu corpo começa a avolumar-se [...]. Agora estou crescendo a olhos vistos, sou enorme, tenho um couro espesso, sou um quadrúpede avantajado, resfolego" (Hilst, 2003a, p. 187). A súbita consciência de que algo está mudando faz emergir do âmago da narradora um novo "eu" - que é ainda ela, mas que é também outra coisa. Enclausurada entre as quatro paredes de seu apartamento, ela sente seu corpo adquirindo proporções descomunais: "quero andar de um lado a outro mas o apartamento é muito pequeno, só consigo dar dois passos, fazer uma volta com sacrifício para dar mais dois passos na direção de onde saí" (p. 187). Conforme tenta se movimentar, a consciência de sua nova estrutura física vai se moldando:

Para ir ao banheiro será preciso entrar no corredor e virar à direita, mas isso é impossível, não posso fazê-lo, meu tamanho é qualquer coisa de espantar, sei finalmente que sou alguém de um tamanho insólito. Olho para os lados com melancolia, fico parado durante muito tempo, estou besta de ter acontecido isso justamente para mim. Recuo e o meu traseiro bate na janela. Inclino-me para examinar as minhas patas mas nesse instante fico encalacrado porque alguma coisa que existe na minha cabeça enganchou-se na parede. Meu Deus, um corno. Eu tenho um corno. Sou unicórnio (Hilst, 2003a, p. 188).

É a forma de um unicórnio, portanto, que assume o duplo da narradora: duplo que se apresenta enquanto materialização de uma identidade multifacetada, como se apenas por meio da metamorfose pudesse vir à tona a evidência de que "mil caras" convivem simultaneamente em seu interior. Assumindo-se participante do baile de máscaras (assumindo a impossibilidade de fazer-se homogênea), a narradora deita fora a máscara que usava, e veste a nova máscara de unicórnio.

Diante da transformação, a interlocutora reage: "Espera um pouco, minha cara, depois de 'Metamorfose' você não pode escrever coisas assim. [...] Essa coisa de se saber um bicho de repente não é nada original e além da 'Metamorfose' há 'Os rinocerontes', você conhece?" (Hilst, 2003a, p. 188). As referências remetem às obras A metamorfose (Die Verwandlung, 1915), de Franz Kafka, e O rinoceronte (Rhinocéros, 1959), de Eugène Ionesco. Em ambas, como observa a interlocutora, deparamonos com situações que envolvem metamorfoses, e "O unicórnio" parece carregar certo teor de indiferença diante de um acontecimento absurdo que em ambas também já se fazia notar. A personagem questiona, 
portanto, a originalidade do recurso empregado no texto, como se estivesse acusando a metamorfose da narradora de plágio. Obviamente, o trecho consiste em um exercício metalinguístico: propondo uma intertextualidade com as obras mencionadas, "O unicórnio" deixa de constituir plágio delas para tornar-se algo como o continuador da tradição de que ambas - A metamorfose e $O$ rinoceronte - fazem parte.

Voltando ao unicórnio, sua clausura chama a atenção de algumas pessoas, que - indiferentes ao fato de terem diante de si uma criatura mitológica - tentam socorrê-lo: "será preciso arrebentar as paredes para tirá-lo daqui" (Hilst, 2003a, p. 191). E ainda: "Agora chegou o zelador do prédio com o seu ajudante. Eles têm a marreta nas mãos" (p. 191). A ideia de arrebentar as paredes para liberar o animal, todavia, logo demonstra-se impraticável, então acabam optando por levá-lo pelas escadas. Logo que o transporte é iniciado, no entanto, o unicórnio (que continua desempenhando a função de narrador) sente-se assustado e acaba defecando sobre os presentes:

Uma corda! Quem tem uma corda! Aqui está, madame - diz o zelador - agora é só puxá-lo e fazê-lo descer pelas escadas. Alguém me dá um tapa no traseiro, volto a cabeça, começo a tremer enquanto o zelador grita: sai daí, menino, não faz assim, o unicórnio não é de ferro. Começo a descer os degraus e aos poucos vou sentindo uma dor insuportável no ventre. Ah, não é possível, é uma cólica intestinal, paro, mas um grito de alguém que me viu pela primeira vez faz com que eu solte abundantes excrementos líquidos pelos degraus (Hilst, 2003a, p. 192).

O tom escatológico é mantido enquanto o unicórnio vai sendo conduzido para fora do prédio: "eu vou descendo e sujando os degraus. O mau cheiro faz cambalear o ajudante do zelador e eu mesma estou a ponto de morrer" (Hilst, 2003a, p. 193). Notamos, nesse trecho, que o unicórnio ainda se refere a si mesmo no feminino: "eu mesma estou a ponto de morrer". No trecho seguinte, todavia, o masculino é empregado, mostrando que até a própria voz da narrativa sofre metamorfose: “Um caminhão para me levar ao parque. Uma rampa tosca para que eu possa subir. Estou muito comovido porque vou ficar pela primeira vez em contato com toda espécie de gente" (p. 197). A passagem mostra que o narrador-unicórnio foi finalmente libertado de sua clausura, e que um caminhão o aguarda para transportá-lo até um parque. 
Em seu Dicionário de símbolos na arte, Sarah Carr-Gomm descreve o unicórnio da seguinte forma:

O lendário unicórnio era um lindo cavalinho branco, com uma barba de bode e um único chifre no meio da cabeça. Com esse chifre, purificava as águas envenenadas por uma serpente, de modo que os animais pudessem bebê-la. $\mathrm{O}$ unicórnio era forte e extremamente rápido, mas podia ser apanhado por uma virgem, cuja pureza percebia e em cujo colo vinha descansar (Carr-Gomm, 2004, p. 215).

A imagem criada a partir da descrição envolve atributos como beleza, pureza e limpeza. Trata-se, podemos dizer, de uma imagem cristalizada em nosso imaginário e, sempre que pensamos em unicórnios, é a ela que recorremos. Dessa forma, quando lemos que a narradora do texto aqui estudado está se metamorfoseando em unicórnio, por um instante talvez pensemos que todo o seu conflito interior será substituído por uma paz homogênea, e que sua identidade fragmentada em mil caras será suplantada por uma figura bela, pura, "simples como um ovo". Recuperando as palavras de Bravo, trata-se da "busca do melhor eu".

O unicórnio hilstiano, todavia, é um bicho feio, sujo, asqueroso. Seu corpo é desproporcional. Sua figura não possui harmonia. Pelo contrário: é assustadora, incompreensível. O duplo que ele representa é um duplo bizarro: não se manifesta para salvar a narradora de sua condição de incompletude, mas sim para evidenciar que não há salvação possível. Para potencializar sua identidade fragmentada, sua incapacidade de enxergar no mundo um todo homogêneo, sua impossibilidade de construir qualquer significado a partir de uma linguagem que não dá conta de "ir além". O duplo-unicórnio que irrompe das entranhas da narradora diz, evidenciando sua condição absurda: não se pode dizer o indizível.

É o aflorar do duplo na narrativa, portanto, que potencializa a impossibilidade de se criar uma representação homogênea do mundo. O unicórnio é transportado para o parque com a esperança de que sua vida será diferente. Logo percebe, todavia, que não há possibilidade de mudança. Que o transformar-se em outro não aponta para alguma luz terna e esclarecedora. Pelo contrário: aponta apenas para o escuro. Ríspido. Bruto. A solidão continua a mesma. As dificuldades continuam as mesmas. Ou ainda piores, pois se a narradora demonstrava-se impossibilitada de fazer-se entender, para o narrador-unicórnio, seu duplo, é ainda mais frustrante a tarefa de tentar significar qualquer 
coisa que carregue um mínimo de sentido. Enclausurado em sua jaula, exibido como aberração, ele reflete: "tudo tem sido tão difícil. Tentei tantas coisas como meios de expressão, tenho me confundido várias vezes, quero sempre me explicar sem que os outros se ofendam, e chego à conclusão de que sempre me saio mal" (Hilst, 2003a, p. 199). Conforme passa o tempo, ele se entrega ao abandono, e suas palavras, ecoando as reflexões de Camus, revelam a consciência de sua presença absurda em um mundo absurdo: "Há muitos dias que não vejo o zelador. Acho que ele se esqueceu de mim, ou melhor, não se esqueceu, mas acredito que ele simplesmente está farto duma presença tão absurda como a minha" (p. 215216). O abandono total, por fim, o leva à morte:

Agora escutem, sem querer ofendê-los: acho que estou morrendo. Da minha garganta vêm vindo uns ruídos escuros. O zelador está voltando, ele está dizendo: EEEEEEEE, BESTA UNICÓRNIO, você está bem esquisito hoje, hein? Um ruído escuro. Um ruído gosmoso. O zelador está mais perto, me cutuca o focinho: EEEEEEEE, BESTA UNICÓRNIO. É verdade, eu estou morrendo. E eu quero muito dizer, eu quero muito dizer antes que a coisa venha, sabem, eu quero muito dizer que o que eu estou tentando dizer é que... eu acredito eu acredito eu acredito eu acredito eu acredito eu acredito eu acredito eu acredito eu acredito eu acredito eu acredito eu acredito eu acredito eu acredito eu acredito eu acredito eu acredito eu acredito eu acredito eu acredito eu acredito eu acredito eu acredito eu acredito eu acredito eu acredito eu acredito eu acredito eu acredito eu acredito eu acredito eu acredito eu acredito eu acredito eu acredito eu acredito eu acredito eu acredito eu acredito eu acredito (Hilst, 2003a, p. 218-219).

O unicórnio repete quarenta vezes a expressão "eu acredito", e em meio a essa repetição frenética a morte o arrebata, sem permitir que ele acrescente sequer um ponto final à sua fala confusa. Momentos antes do "transe", ele diz sentir que a "coisa" está próxima e, "antes que a coisa venha", ele quer muito dizer alguma coisa. Ele precisa dizer: precisa sentir-se homogêneo pelo menos uma vez: precisa sentir-se capaz de significar. É dessa necessidade - não uma necessidade súbita, mas uma ânsia que o acompanhou a vida toda, antes e depois da metamorfose que surge, às vésperas do fim, a repetição constante da expressão "eu acredito". Porque o unicórnio precisa acreditar que é possível "ir além", que é possível completar alguma coisa. No entanto, quarenta vezes ele 
repete "eu acredito", mas não é capaz de articular nada para além dessa expressão. Não é capaz de dizer qual é o objeto dessa crença. Assim como aconteceu em toda a sua vida, sua tentativa derradeira de significar acaba em falha.

Analisando a obra de Sören Kierkegaard, Camus observa: "O homem que escreve: 'O mais seguro dos mutismos não é calar-se, mas falar', de partida se assegura que nenhuma verdade é absoluta e não pode tornar satisfatória uma existência impossível em si mesma" (Camus, 2008, p. 39). Podemos fazer de tais palavras o epitáfio do unicórnio, pois é para o silêncio que aponta sua fala em excesso. O desdobrar-se em mil vozes, em mil caras, o fazer irromper das entranhas um duplo de proporções bestiais, ilógicas, na tentativa desesperada de construir uma representação coerente do mundo - mesmo sabendo que não é possível construir tal representação -, é levar a linguagem aos seus limites, à exaustão que aponta para a falha. Na quietude profunda de seu momento final, o unicórnio repete "eu acredito" quarenta vezes, mas sabe que, no fundo, não acredita em nada. Na quietude profunda de seu momento final, suas palavras evidenciam que ele é o personagem de mil caras, e em cada uma de suas mil caras estampa-se a consciência de que é impossível dizer o indizível.

\section{Referências}

BRAVO, Nicole Fernandez (2005). Duplo. In: BRUNEL, Pierre (org). Dicionário de mitos literários. 4. ed. Tradução de Carlos Sussekind, Jorge Laclette, Maria Thereza Rezende Costa, Vera Whately. Rio de Janeiro: José Olympio

CAMUS, Albert (2008). O mito de Sísifo. 6. ed. Tradução de Ari Roitman e Paulina Watch. 6. ed. Rio de Janeiro, São Paulo: Record.

CARR-GOMM, Sarah (2004). Dicionário de símbolos na arte: guia ilustrado da pintura e da escultura ocidentais. Tradução de Marta de Senna. Bauru: Edusc.

HILST, Hilda (2003a). O unicórnio. In: Fluxo-floema. São Paulo: Globo. (2003b). Lázaro. In: Fluxo-floema. São Paulo: Globo.

NIETZSCHE, Friedrich Wilhelm (1997). Acerca da verdade e da mentira no sentido extramoral. In: Obras escolhidas de Friedrich Nietzsche. Vol. I. Tradução de Helga Hoock Quadrado. Lisboa: Relógio de Água. 
ROSSET, Clément (2000). Le monde et ses remèdes. 2. ed. Paris: Presses Universitaires de France.

Recebido em abril de 2013.

Aprovado em setembro de 2013.

\section{resumolabstract}

\section{A impossibilidade de se dizer o indizível: reflexões sobre o duplo na novela "O unicórnio", de Hilda Hilst}

Willian André

O objetivo deste estudo é refletir sobre a manifestação do duplo na novela "O unicórnio", de Hilda Hilst, como evidência da impossibilidade de se expressar aquilo que não pode ser expresso. Ecoando a experiência insólita de Gregor Samsa, a narradora dessa novela vê-se subitamente transformada em uma criatura desproporcional, absurda. Duplo da narradora, esse novo "eu" que ela se torna explicita a tortuosa relação, que percorre todo o texto, entre uma profunda necessidade de se compreender o mundo e um mundo que se fecha ríspido em seu silêncio, negando-se a ser compreendido. Interpretando o surgimento do duplo-unicórnio como marca principal dessa confrontação, esperamos esboçar, nas próximas linhas, algumas reflexões sobre os limites da linguagem diante do indizível.

Palavras-chave: "O unicórnio", duplo, limitações da linguagem, Hilda Hilst.

\section{The impossibility of speaking the unspeakable: reflections on the double in the novella "O unicórnio", by Hilda Hilst}

Willian André

This study aims at reflecting on the raise of the double in the novella "O unicórnio", by Hilda Hilst, as an evidence of one's impossibility to express what cannot be expressed. Echoing Gregor Samsa's uncanny experience, the novella's narrator suddenly becomes an awkward, absurd creature. A double of the narrator, this new "I" she becomes makes explicit the devious relation, built throughout the text, between a deep necessity of comprehending the world and a world that is closed in its silence, denying to be comprehended. Interpreting the raise of this double-unicorn as the main evidence of this confront, we hope to draw, in the following lines, some reflections on the limits of the language in face of the unspeakable.

Keywords: “O unicórnio", double, limitations of language, Hilda Hilst. 